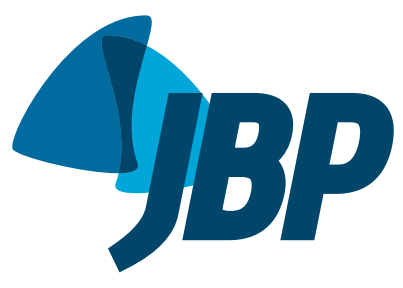

\title{
Sweat test and cystic fibrosis: overview of test performance at public and private centers in the state of São Paulo, Brazil
}

\author{
Maria Fátima Servidoni1,2, Carla Cristina Souza Gomez ${ }^{1}$, \\ Fernando Augusto Lima Marson ${ }^{1,3}$, Adyléia Aparecida Dalbo Contrera Toro', \\ Maria Ângela Gonçalves de Oliveira Ribeiro', José Dirceu Ribeiro', \\ Antônio Fernando Ribeiro'; Grupo Colaborativo de Estudos em Fibrose Cística
}

1. Departamento de Pediatria, Faculdade de Ciências Médicas, Universidade Estadual de Campinas - Unicamp Campinas (SP) Brasil.

2. Gastrocentro - Unidade de Endoscopia, Faculdade de Ciências Médicas, Universidade Estadual de Campinas Unicamp - Campinas (SP) Brasil.

3. Departamento de Genética Médica, Faculdade de Ciências Médicas, Universidade Estadual de Campinas Unicamp - Campinas (SP) Brasil.

Submitted: 18 March 2016

Accepted: 6 January 2017

Study carried out at the Faculdade de Ciências Médicas, Universidade Estadual de Campinas - Unicamp - Campinas (SP) Brasil.

\begin{abstract}
Objective: The sweat test (ST) measures chloride levels in sweat and is considered the gold standard for the diagnosis of cystic fibrosis (CF). However, the reliability of a ST depends on their being performed by experienced technicians and in accordance with strict guidelines. Our aim was to evaluate how sweat stimulation, sweat collection, and chloride measurement are performed at 14 centers ( 9 public centers and 5 private centers) that routinely perform STs in the state of São Paulo, which has the highest frequency of CF in Brazil. Methods: This was a cross-sectional cohort study, using a standardized questionnaire administered in loco to the staff responsible for conducting STs. Results: No uniformity regarding the procedures was found among the centers. Most centers were noncompliant with the international guidelines, especially regarding the collection of sweat (the samples were insufficient in $10-50 \%$ of the subjects tested); availability of stimulation equipment (which was limited at 2 centers); modernity and certification of stimulation equipment (most of the equipment having been used for 3-23 years); and written protocols (which were lacking at 12 centers). Knowledge of ST guidelines was evaluated at only 1 center. Conclusions: Our results show that STs largely deviate from internationally accepted guidelines at the participating centers. Therefore, there is an urgent need for standardization of STs, training of qualified personnel, and acquisition/ certification of suitable equipment. These are essential conditions for a reliable diagnosis of $\mathrm{CF}$, especially with the increasing demand due to newborn screening nationwide, and for the assessment of a possible clinical benefit from the use of modulator drugs.

Keywords: Cystic fibrosis/diagnosis; Cystic fibrosis/prevention \& control; Sweat.
\end{abstract}

\section{INTRODUCTION}

The early observations of salty sweat in cystic fibrosis (CF) led to the development of the "still" gold standard test for CF diagnosis, consisting in the measurement of sweat chloride $\left(\mathrm{Cl}^{-}\right)$and sodium $\left(\mathrm{Na}^{+}\right)$concentrations. For most of the patients with $\mathrm{CF}$, at least those with classical CF, this assay will reveal elevated levels of both electrolytes, confirming a diagnosis of CF by this relatively straightforward sweat test (ST).

As in many other countries, ${ }^{(1)}$ the implementation of newborn screening (NBS) for CF in Brazil challenged the diagnosis paradigm by leading to the routine diagnosis of various asymptomatic children. In 2001, NBS was initiated in some states in Brazil, the Brazilian Unified Health Care System providing a nationwide coverage in 2014 (Appendix 1; available in the online version of the JBP; http://www.jornaldepneumologia.com.br/ detalhe_anexo.asp?id=48). Although the incidence of CF ranges from $1: 2,500$ to $1: 6,000$ live births in Europe and
North America, ${ }^{(2)}$ the estimated incidence is $1: 10,000$ live births in Brazil. ${ }^{(3)}$ Based on these data, it is estimated that 60 new CF cases occur per year in the state of São Paulo (SP). NBS for CF caused an increase in the survival of these patients since it enabled the early diagnosis of CF and allowed the adoption of nutritional and therapeutic approaches before the advent of clinical manifestations and complications of the disease, ${ }^{(4-6)}$ being economically justifiable for the public health care initiative. ${ }^{(7)}$ In the first month of life of an individual, NBS is carried out by two determinations of the level of immunoreactive trypsinogen. However, the follow-up of the patients with positive results in NBS requires the confirmation of a diagnosis of CF. This is achieved by ST values $\geq 60$ $\mathrm{mEq} / \mathrm{L}$ in two different samples and/or the identification of two mutations in the cystic fibrosis transmembrane conductance regulator (CFTR) gene. ${ }^{(8)}$

Although the ST remains the most sensitive indicator of $\mathrm{CF}$, in order to be considered as the "gold standard", it should be performed using the Gibson and Cooke (GC)

Correspondence to:

Maria Fátima Servidoni and José Dirceu Ribeiro. Faculdade de Ciências Médicas, Universidade Estadual de Campinas, Rua Tessália Vieira de Camargo, 126, Cidade

Universitária, CEP 13083-887, Campinas, SP, Brasil.

Tel.: 5519 3521-8983 or 5519 3521-8959. Fax: 5519 3521-8970. E-mail: mfservidoni@hotmail.com or jdirceuribeiro@gmail.com

Financial support: Fernando Augusto Lima Marson received financial support from Fundação de Amparo à Pesquisa do Estado de São Paulo (FAPESP, São Paulo Research Foundation; Grant nos. 2011/12939-4 and 2015/12858-5) and from the Fundo de Apoio ao Ensino, à Pesquisa e Extensão da Universidade Estadual de Campinas (FAEPEX, Support Fund Research, Education and Extension of State University at Campinas; Grant no. 0648/2015). 
technique, also called the quantitative pilocarpine iontophoresis ST. ${ }^{(9)}$

For the GC method to be reliable, it needs to be performed in laboratories with experienced and skilled technicians according to strict guidelines, ${ }^{(10)}$ requiring that sweating be stimulated by pilocarpine iontophoresis; sweat is collected on a filter paper or gauze pad, weighed, eluted, and analyzed for $\mathrm{Na}^{+}$and $\mathrm{Cl}^{-}$using a variety of validated methods described below. The Cystic Fibrosis Foundation summarized its guidelines in 23 topics in order to ensure the appropriate quality of STs. ${ }^{(11,12)}$ The topics are based on the classical GC method of pilocarpine stimulation, ${ }^{(9)}$ use of filter paper or Macroduct ${ }^{\circledR}$ Sweat Collection System (MSCS; EliTechGroup, Paris, France) for sweat collection, and determination of $\mathrm{Cl}^{-}$by manual titration or by a coulometric quantitative test. ${ }^{(9,10,12-15)}$ The qualitative method is not accepted for confirming a definitive diagnosis of CF. ${ }^{(10,13,16)}$

Indeed, the ST is complex, and its accuracy is related to the competence and commitment of the professional who carries out its various steps. ${ }^{(9,10)}$ For this reason, various countries organized standardized protocols for STs. The first country to publish a consensus standardization and external quality control for STs was the USA in 1994, followed by the United Kingdom in 2000. ${ }^{(17-20)}$ Since then, numerous guidelines have been published, enforcing specific rules to be adopted while carrying out STs, as well as demanding accreditation and periodic monitoring of the laboratories by official regulatory agencies. ${ }^{(13)}$

Nevertheless, even in countries where the standardization of STs is well established, there are details in the performance and interpretation of the tests that are often omitted and overlooked from center to center. ${ }^{(12,21)}$ Moreover, the ST has also become a major outcome measure in clinical trials, namely those involving CFTR modulators that rescue the function of the dysfunctional mutant protein. ${ }^{(22,23)}$ Therefore, it has become increasingly relevant that the performance and the standard procedures of STs should be reviewed at present times.

Taking into account the socioeconomic status and the miscegenation of the Brazilian population, the importance of STs and other methods for the diagnosis of $\mathrm{CF}$ is even more relevant.(24-28) In Brazil, to date, there is no critical and comparative analysis regarding the performance and the interpretation of STs. We selected the state of SP because it is the most populous in Brazil, with approximately 45 million inhabitants in 2016 (Appendix 2 ; available in the online version of the JBP; http://www.jornaldepneumologia.com.br/ detalhe_anexo.asp?id=48). ${ }^{(29)}$

The objective of the present study was to evaluate how STs are performed and interpreted at the centers that agreed to participate in the study and that routinely perform these tests in various cities in the state of $\mathrm{SP}$, comparing their routine with those specified in international guidelines. These centers, altogether, carry out approximately 4,500 tests per year.

\section{METHODS}

This was an observational, descriptive, cross-sectional cohort study. A total of 18 centers that routinely perform STs in the state of SP were invited to participate in the study in 2013. The study was approved by the Research Ethics Committee of the Universidade Estadual de Campinas (State University of Campinas; Protocol no. 86624/2012) and was carried out in accordance with the Declaration of Helsinki. All participants gave written informed consent.

A questionnaire was developed, consisting of 54 questions that comprised all of the steps for performing STs: sweat stimulation; collection of sweat; and determination of the level of $\mathrm{Cl}^{-(12,13)}$ (Appendix 3 ; available in the online version of the JBP; http:// www.jornaldepneumologia.com.br/detalhe_anexo. asp?id=48). The questionnaire was given to the staff responsible for conducting the STs at all of the centers included in the study. In our study, two researchers performed the interviews simultaneously. The data were compiled in Excel spreadsheets, and the results were presented in tables and figures.

\section{RESULTS}

A total of 18 centers were identified as performing STs as part of their routine ( 9 were private and 9 were public). Of the 18 centers, 14 agreed to participate in the study, $5(35.7 \%)$ being private institutions and 9 $(64.3 \%)$ being public health care centers (Figure 1 ). At the moment of the visit, 4 of the centers were not performing STs by lack of supplies. The 14 centers included in the study perform approximately 4,500 STs/ year, 4,000 of those being carried out at public centers. The number of STs/year per center is shown in Figure 2. Among the 14 centers, the length of experience in performing STs ranged from 1 to $>20$ years (Appendix 4 ; available in the online version of the JBP; http:// www.jornaldepneumologia.com.br/detalhe_anexo. asp?id=48).

We interviewed the professionals involved in the performance of the three stages of STs at the participating centers. Regarding their occupation, one was a physician, seven were biomedical technicians, two were biologists, four were nurses, and seven were nursing technicians. Among the 14 centers, 11 professionals were trained by colleagues from the same center (internal training), 2 were trained at another center (external training), and 1 had both internal and external training. Only 1 of the centers was aware of the ST guidelines and had a printed version of the standard operating procedure manual.

Among the 14 centers, 2 had no equipment for sweat stimulation. Some centers used more than one device, the equipment used being nine MSCS; one CF-Indicator ${ }^{\circledR}$ (Polychrome Medical Inc., Brooklyn Center, MN, USA); five Iontokit ${ }^{\circledR}$ (Advanced Instruments Inc., Norwood, MA, USA); and one produced by Qualiterm (Qualiterm, São Paulo, Brazil). The five devices connected to a power grid were as follows: three Iontokit ${ }^{\circledR}$ (Advanced 

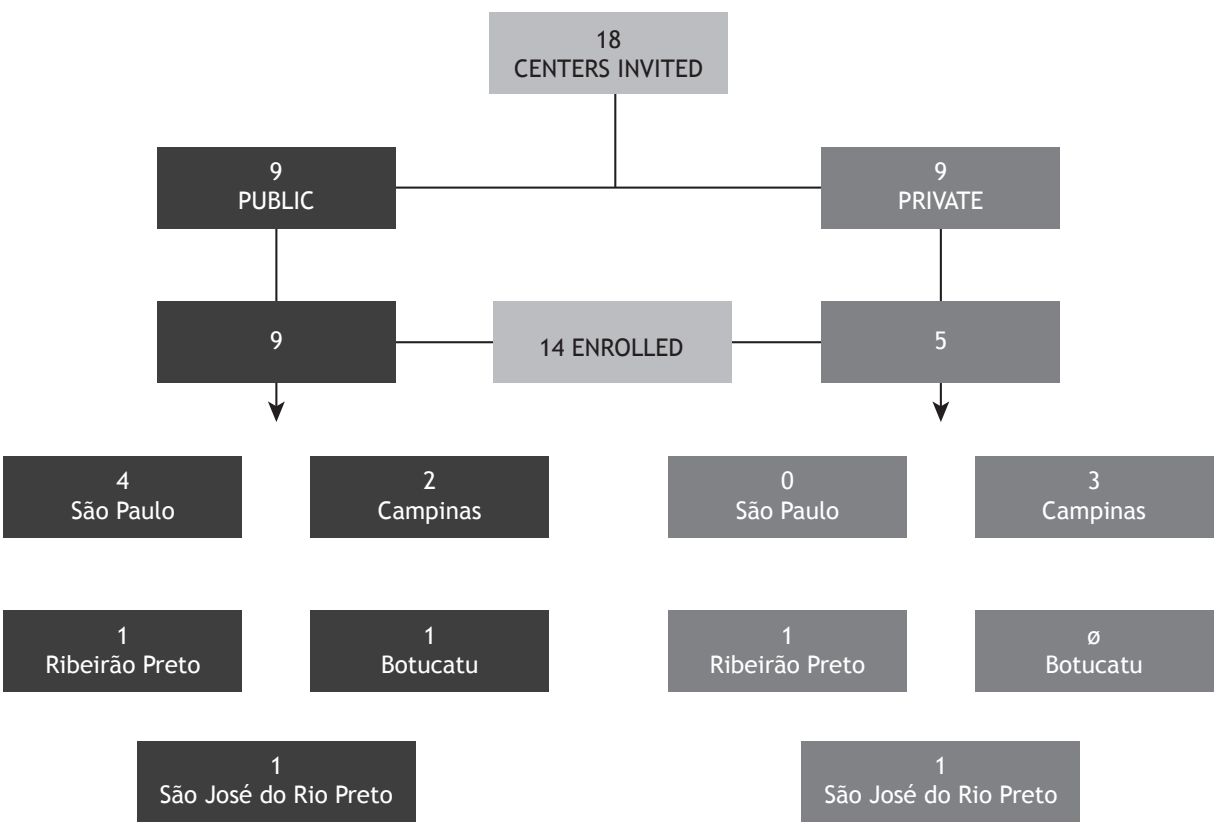

Figure 1. Participating referral centers for cystic fibrosis in the state of São Paulo according to the cities where they are located in.

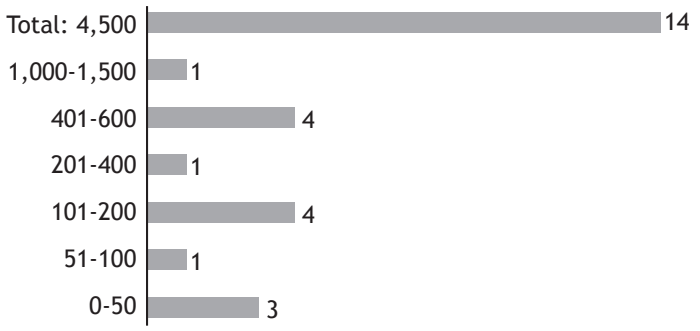

Figure 2. Number of sweat tests performed per year per center. From 0 to 50 tests: two private centers and one public center; from 51 to 100 tests: one private center; from 101 to 200 tests: three public centers and one private center; from 201 to 400 tests: one private center; and from 401 to 1,500 tests: five public centers. Total $=4,500$ tests/year at the 14 centers.

Instruments Inc.), one Iontoplus ${ }^{\circledR}$ (NAIMCO Inc., Chattanooga, TN, USA); and one handmade craft. These devices were older, with a mean usage time of 15 years (Figure 3 ).

There were 21 pieces of stimulation equipment at 12 of the centers altogether. None of the pieces of equipment had an official registration for the clinical diagnosis of CF in the country. Among these, there were $8 \mathrm{MSCS}, 7$ of which not being in operation due to lack of spare parts or supplies, or because they broke down less than a year ago. Among the 12 centers that carried out sweat stimulation, 8 used the forearm/arm for electrode placement, whereas the other 4 used other sites (Figure 4A). Sweat stimulation was achieved by one or more of the following techniques: use of a blanket, at 6 centers; use of a coat, at 6 ; running or walking outdoors, at 4 ; skin lock with plastic wrap, at 2 ; use of a bandage, at 1 ; and Parafilm wrapping, at

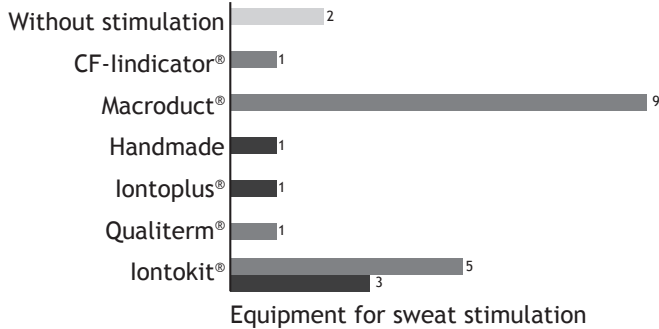

Without stimulation Battery Electric grid

Figure 3. Sweat stimulation equipment used in the centers regarding the energy source used. None was licensed by the Brazilian National Health Oversight Agency. CF-Indicator ${ }^{\circledR}$ (Polychrome Medical Inc., Brooklyn Center, MN, USA); Macroduct ${ }^{\circledR}$ Sweat Collection System (EliTechGroup, Paris, France); Iontoplus ${ }^{\circledR}$ (NAIMCO Inc., Chattanooga, TN, USA); Qualiterm (Qualiterm, São Paulo, Brazil); and Iontokit ${ }^{\circledR}$ (Advanced Instruments Inc., Norwood, MA, USA).

1. Sweat was collected from the patient with the help of a disposable spoon and placed into a sterile tube for the determination of the level of $\mathrm{Cl}^{-}$at 1 center. At 2 private centers, sweat was induced without stimulation by iontophoresis devices (Appendix 5 ; available in the online version of the JBP; http:// www.jornaldepneumologia.com.br/detalhe_anexo. asp?id=48).

The electrical stimulation time to induce sweat ranged from 3 to $10 \mathrm{~min}$ (Figure 4B). The type of current used was known at only 3 of the 14 centers (direct current) and unknown at 9, 5 of which also failed to report the intensity of the current used. The intensity of the current was known at 5 centers (Figure 4C). At 4 centers $(28.6 \%)$, it was reported that the electrical stimulation procedure had caused skin burn in some 


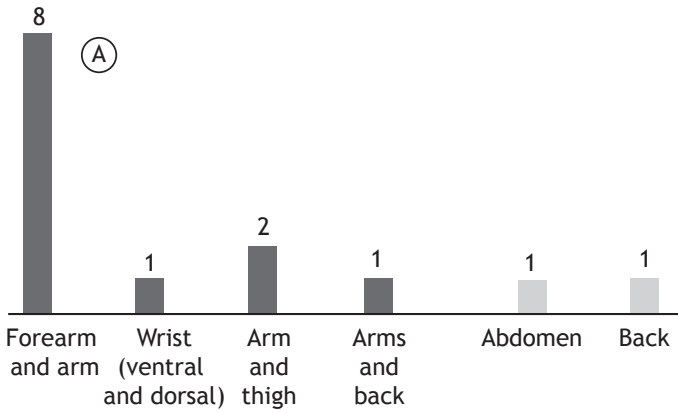

- Site for stimulation and collection Site for collection Site for stimulation and collection

(C)

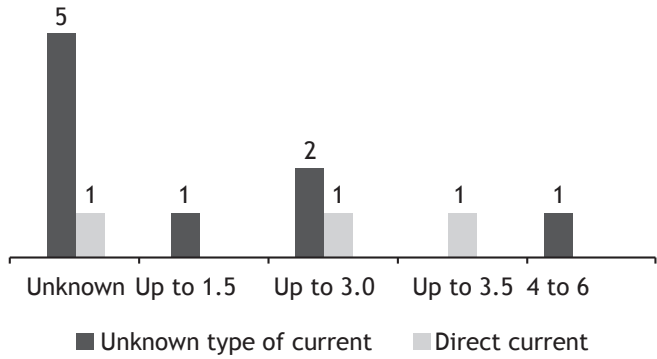

Current intensity $\left(\mathrm{mA} / \mathrm{cm}^{2}\right)$

(E)

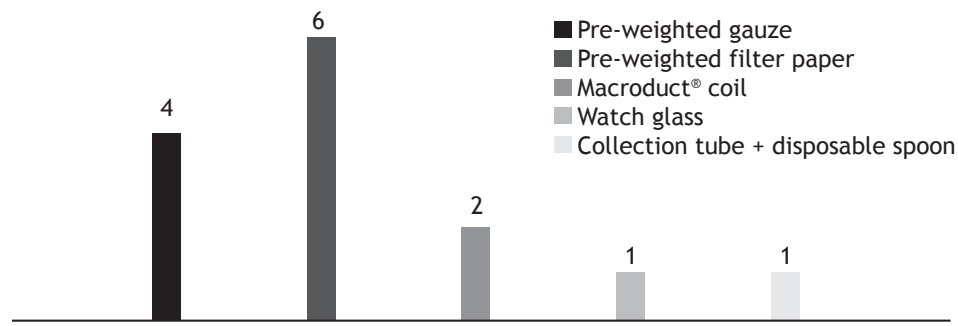

Materials for sweat collection

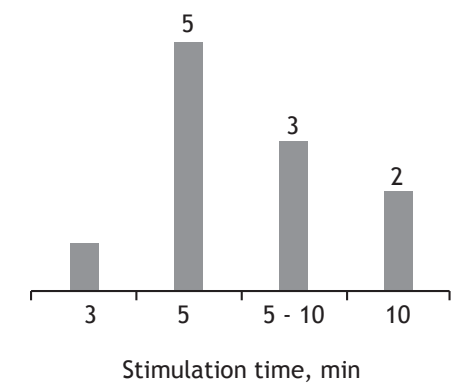

(D)

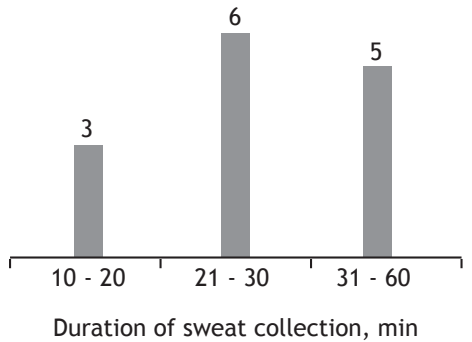

Duration of sweat collection, $\mathrm{min}$

Figure 4. In $A$, site for stimulation and collection of sweat in the 12 participating centers that performed sweat stimulation.
In $B$, stimulation time to induce sweat per center. In $C$, information available regarding the type and the intensity of the current applied for sweat stimulation per center. In $D$, duration of sweat collection per center. In $E$, materials employed for sweat collection per center.

patients; however, 5 centers $(35.7 \%)$ reported that it had never occurred with any of their patients, whereas 3 centers (21.4\%) were unable to report that information since the interviewees had been recently working at those centers. Finally, 2 centers (14.3\%) did not use electrical stimulation.

The duration of sweat collection ranged from 10 to $60 \mathrm{~min}$ (Figure 4D). The materials employed for sweat collection at the 14 centers are described in Figure $4 \mathrm{E}$. It is of note that 2 centers were using unusual materials/techniques: a watch glass was placed over the site of pilocarpine stimulation, then fixed with tape, and the sweat droplets were collected using a sterile pipette or a disposable spoon into a sterile tube at 1 of the centers, whereas the other center did not have appropriate precision scales for weighing the collected material. In addition, 2 centers did not perform sweat stimulation using any kind of equipment and, therefore, were disregarded regarding this issue.

The $\mathrm{Cl}^{-}$level was determined by using the manual titration technique and the quantitative coulometric test (chloridometer), at 6 centers each. Among the latter, 1 center was not in operation. The need to repeat a ST was due to insufficient sweating and unknown causes at 10 and 4 of the centers, respectively. The rate of repeat STs was 5\%, at 1 center; $10-20 \%$, at $7 ; 30 \%$, at 1 ; and $>50 \%$, at 1 .

The number of people who collected sweat and conducted the STs is summarized in Figure 5A. The same professional was responsible for the collection and the performance of the ST at 6 centers. The 
minimum acceptable amount of sweat in order to conduct a reliable ST considerably varied among the centers and is summarized in Figure 5B. At 11 centers that used filter paper or gauze to collect sweat, the amount of sweat considerably ranged from 50 to 100 $\mathrm{mg}$, and 1 center had no knowledge of the acceptable value (Figure 5B). Regarding the 3 centers using the MSCS, the acceptable volume of sweat was $15 \mu \mathrm{L}, 20$ $\mu \mathrm{L}$, and no standard. The center that used the watch glass reported that the required minimum volume was $20 \mu \mathrm{L}$. Most of the professionals at the centers were unaware of the correct number of tests with positive

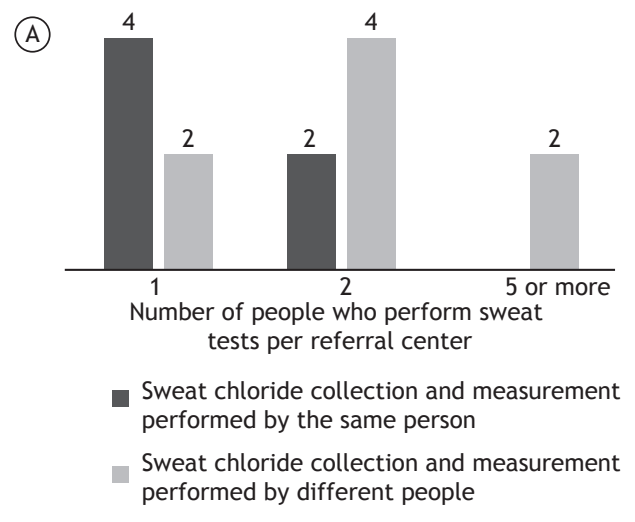

(B)

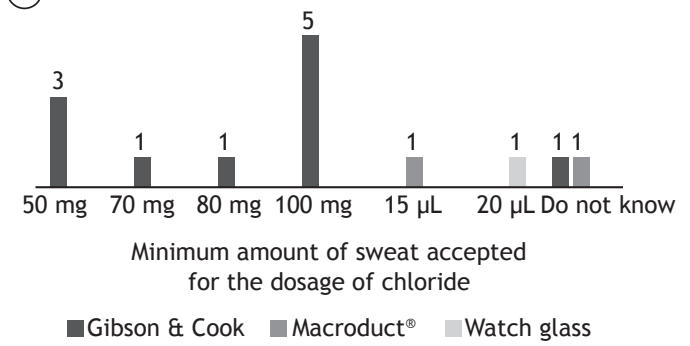

(C)

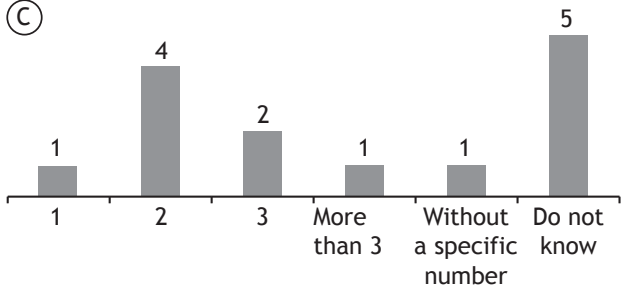

Number of abnormal sweat test results to confirm the diagnosis of cystic fibrosis

Figure 5. In A, number of people who perform sweat tests (collection and quantification of chloride) per center. In six centers, the staff is responsible for collecting sweat and determining the level of chloride in it. In eight centers, the staff that collects sweat is not the same as that determining the level of chloride. In those centers, the laboratory team is responsible for determining the level of chloride. In $B$, knowledge of the professionals involved in the performance of sweat tests about the minimum acceptable amount of sweat for chloride level determination per collection method per center. In C, knowledge of the professionals involved in the performance of sweat tests about the necessary number of abnormal test results in order to confirm the diagnosis of cystic fibrosis per center. results $\left(\mathrm{Cl}^{-} \geq 60 \mathrm{mEq} / \mathrm{L}\right)$ for a definitive diagnosis of CF (Figure 5C). Figure 6 shows how compliant with the Cystic Fibrosis Foundation guidelines ${ }^{(13)}$ each of the 14 centers was.

\section{DISCUSSION}

In Brazil, the diversity of expression of the disease is conditioned by miscegenation, which highly increases the genetic diversity expressed in a variability of mutations in the CFTR gene in our population, thus rendering the genetic diagnosis difficult and costly. The monitoring of CF patients in Brazil is performed at referral centers, most of which are public and linked to the Brazilian Unified National Health Care System with public financial support and generally associated with universities. The state of SP has the second per capita income in the country and has the largest number of referral centers for $\mathrm{CF}(n=7)$, all of which being public health care centers (Appendix 6 ; available in the online version of the JBP; http://www.jornaldepneumologia. com.br/detalhe_anexo.asp?id=48).

The present study on the performance of STs at 14 centers, which perform 4,500 tests/year altogether, revealed that there is no uniformity in the ST procedures and that there are serious difficulties in its performance and significantly inadequate conditions, which largely deviate it from internationally accepted guidelines.

Similar studies, however, had been previously performed regarding the quality of STs at various centers in several other countries, also presenting significant diversity and inconsistent results. ${ }^{(12,30,31)}$ The diagnostic confirmation of CF enables health care centers to provide better care and monitoring, which translates into higher life expectancy for the patients. ${ }^{(8)}$ This was also found at our referral center. ${ }^{(32)}$ The standardization of STs is key to a reliable diagnosis of CF.

In particular, the present study has shown that there is no uniformity in the performance of ST in its three stages (stimulation, collection, and quantification) at the participating centers. The main issues and possible alternatives to the three steps can be summarized as follows:

(i) Stimulation: the lack of awareness about the existence of adequate equipment for sweat stimulation and its usage was present at approximately $30 \%$ of the participating centers. Alternative methods of stimulation, noncompliant with the international guidelines (e.g. exposure to the sun with a blanket, exposure to the sun inside a car, usage of noncertified sweat induction equipment, and lack of knowledge of stimulation techniques), were in practice at 4 of the centers and might even impair the health of patients (e.g. skin burning, dehydration, or even death). In addition, those 4 centers also collected inadequate sweat samples for determining the level of $\mathrm{Cl}^{-}$. Every center should rely on the iontophoresis stimulation technique with pilocarpine, use certified stimulation equipment, and carry out its regular maintenance and calibration 


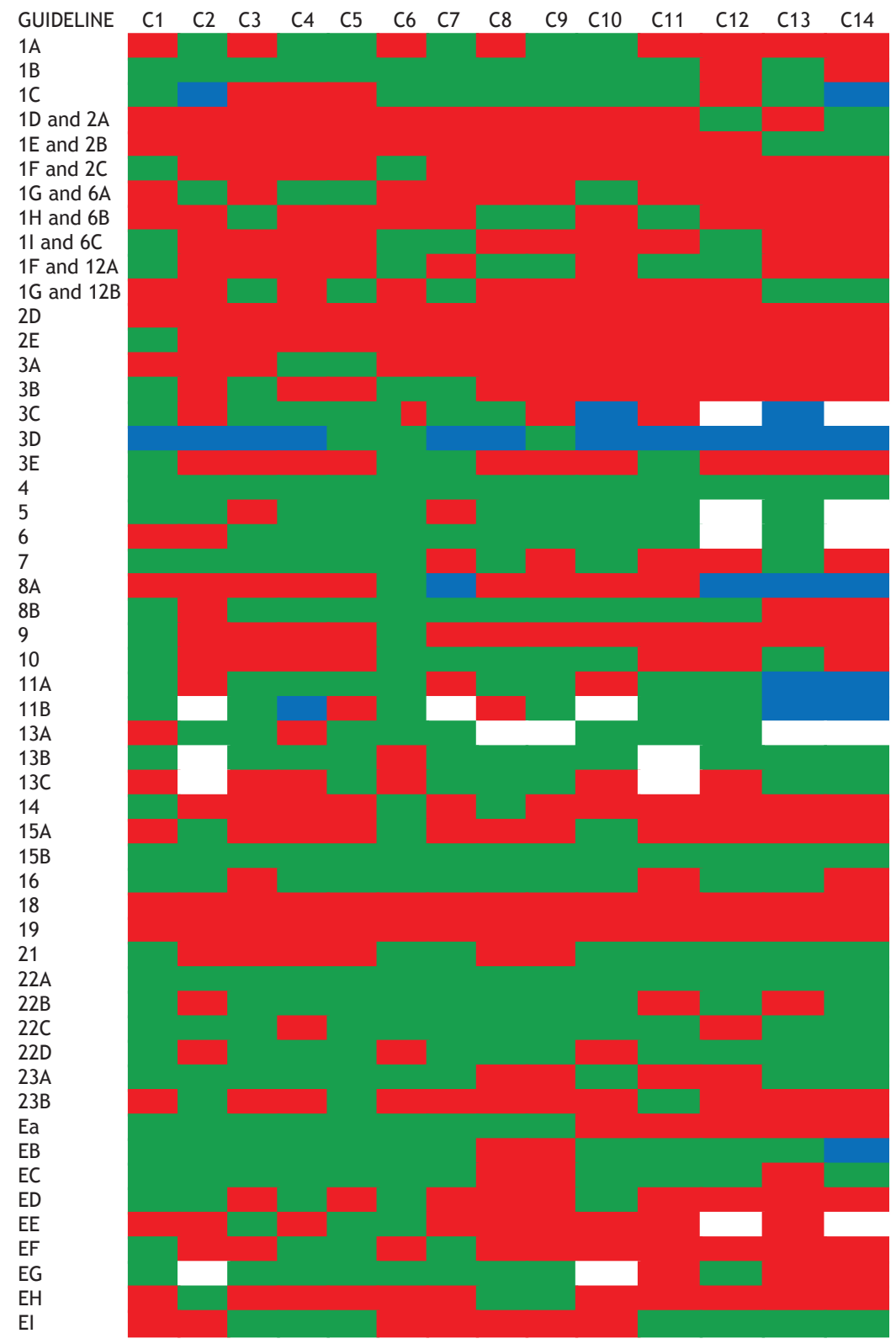

Figure 6. Compliance with the sweat test guidelines by LeGrys et al. ${ }^{(13)}$ per center. 1A: Macroduct ${ }^{\circledR}$ coils available; $1 \mathrm{~B}$ : Stimulation of sweat using pilocarpine iontophoresis; 1C: Evaluation of the amount collected either in weight (mg) or volume $(\mu \mathrm{L}) ; 1 \mathrm{D}$ and $2 \mathrm{~A}$ : without sweat stimulation; $1 \mathrm{E}$ and $2 \mathrm{~B}$ : inadequate collection method (alternative methods); $1 \mathrm{~F}$

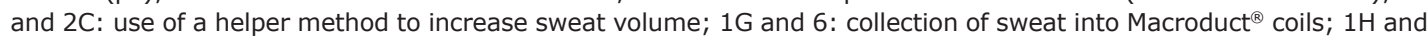
6B: collection of sweat on filter paper; 1I and 6C: collection of sweat in gauze; $1 \mathrm{~F}$ and 12A: chloride level determined by manual titration, using the Schales and Schales mercuric nitrate procedure; $1 \mathrm{G}$ and $12 \mathrm{~B}$ : chloride level determined by coulometric titration, using a chloridometer; 2D: following the US National Committee for Clinical Laboratory Standards guidelines ${ }^{(17)} ; 2 \mathrm{E}$ : laboratory must have access to a copy of the guidelines ${ }^{(17)}$ (paper copy or electronic file); 3A: iontophoresis equipment must be battery powered and regularly inspected; 3B: iontophoresis equipment powered by electrical network; 3C: iontophoresis performed with electrode lead; 3D: knowledge about the current applied; 3E: inspection for current control and leakage must be periodically performed by biomedical engineering according to the manufacturer's recommendations; 4: the minimum age for testing is 48 hours of life; 5 : arms or legs were used as collection sites, and the iontophoresis current should not cross the heart; 6 : iontophoresis should be carried out using pilocarpine for $5 \mathrm{~min}$; 7: sweat collected for no more than $30 \mathrm{~min}$; 8A: the incidence of insufficient samples was investigated and resolved if it exceeded $5 \%$ for patients older than three months of age; $8 \mathrm{~B}$ : exclusion criteria were adopted; 9: collection and analysis were performed in duplicate; 10A: insufficient samples were not analyzed and were not pooled for analysis; 11A: collection and analytical procedures were designed to minimize evaporation or contamination; 11B: sweat collected in gauze, once reweighed, was stored with or without diluents in a tightly sealed container for up to 3 days at refrigerator temperature; 13A: performing and evaluating quality control in every sweat analysis run in order to determine quality control; 13B: a control sample was assayed with each patient run; 13C: a 
positive and negative control (or more) were assayed with each patient run; 14: sweat tests are included in the overall evaluation of continuous quality improvement in the laboratory; 15A: reagents were appropriately labeled; 15B: sweat samples were appropriately labeled for patient identification throughout the process of sweat collection and analysis; 16: appropriate reference values for chloride in sweat were used; 18: laboratories document successful performance in the Brazilian National Health Oversight Agency proficiency testing survey for sweat test analysis; 19: the director of the center reviews all sweat test results by using procedures consistent with Health Insurance Portability and Accountability Act of 1996 regulations; and 21: all positive tests were confirmed with a repeat sweat chloride test. Red: noncompliant with the guidelines; green: compliant with the guidelines; white: not evaluated; and blue: no data.

by the manufacturer or a qualified company in order to ensure the safety of the procedure. Every center should also provide (or seek elsewhere) adequate training of the professionals responsible for handling the equipment.

(ii) Collection: most of the participating centers used methods for sweat collection that were in accordance with the established recommendations (use of filter paper, gauze, or MSCS). However, 2 centers used alternative, nonrecommended collection methods (use of a spoon and a watch glass), which affect the reliability of the ST. Although MSCS has been described as a suitable method for the collection of sweat by the US Health Department since 2013, it was not registered in Brazil during the period of study. ${ }^{(13)}$ In September of 2014 , the use of MSCS was properly licensed, as well as of the digital chloridometer, which enabled adequate, periodic maintenance of the equipment and uninterrupted acquisition of supplies. This fact will possibly change the present scenario: 7 centers were not using MSCS due to the lack of spare parts/supplies, difficulties in the maintenance of the equipment, or lack of trained professionals capable of using the system (how to perform sweat induction, sweat collection, and $\mathrm{Cl}^{-}$level determination). Another factor to be considered is the high cost of supplies, which are imported, in comparison with the traditional method of stimulation and collection for the GC method, which uses pilocarpine and filter paper or gauze for sweat collection.

(iii) Quantification: The determination of the $\mathrm{Cl}^{-}$level must be quantitative and performed by coulometry, flame photometry, or manual titration. Regardless of the procedure, there were no problems regarding this issue at the participating centers, except that conductivity, which is an unreliable procedure, was used for the diagnosis of CF at 2 centers. At another center, conductivity was used just for screening, which is an appropriate, correct approach.

$\mathrm{CF}$ is a progressive disease, which requires that patients be treated at referral centers so as to receive the best health care and adequate treatment. Having a safe, reliable diagnosis is the first step, and it is critical for the guidance of patients and their families by the medical staff.

The present study shows the real situation of STs in the state of SP, which may be representative of the overall situation for STs in Brazil. Altogether, our results show that STs largely deviate from internationally accepted guidelines at the participating centers. There is an urgent need for either domestic or imported equipment for sweat stimulation and for determining the level of $\mathrm{Cl}^{-}$in sweat in accordance with international guidelines. Maintenance should be adequate, and spare parts and supplies should be always available so that the results obtained are reliable and appropriate.

From this unique moment, when we celebrate the introduction of NBS for CF in all states in Brazil, we must be prepared to overcome the challenges ahead. These challenges can only be overcome if they are first identified and objectively faced by the CF teams. In addition, we need to work together so as to change the current reality; we believe that we can only build a new reality if we first become aware of the limitations and difficulties inherent to each individual center.

The present study provides a warning regarding the need for standardization of STs in Brazil by means of the construction and adoption of guidelines for the diagnosis of $\mathrm{CF}$. The issue has been in the discussion agenda of the Brazilian CF Study Group.

Directors of CF referral centers should review each current step in the performance of STs, working closely together with the laboratory staff, which will undoubtedly improve the quality of the results so as to provide a reliable CF diagnosis and minimize the possible bias of STs. The professionals who perform STs should be aware of the specificities of the disease and recognize the important role of a correctly performed ST to confirm or exclude a diagnosis of CF. Such training should be provided by the CF referral centers to its professionals, fostering their participation in internal or external training, scientific events, and other discussion forums. The proximity among the different professionals working in the area of $\mathrm{CF}$, as well as the exchange of information among the different referral centers, will allow to increasing the knowledge regarding STs and, therefore, improve the procedures involved in it toward a more reliable diagnosis of CF.

In conclusion, we found no uniformity in the steps carried out in the performance of STs and large deviations from internationally accepted ST guidelines at the various participating centers in the state of SP. Major inadequate conditions included insufficient production of sweat, lack of stimulation equipment or clinical chemistry equipment, absence of written protocols, and use of obsolete noncertified measuring equipment. Even though we know that there are various difficulties and barriers to be overcome, we need to move towards meeting the 23 topics of the Cystic Fibrosis Foundation guidelines ${ }^{(13)}$ so that STs are adequately carried out to this end. 
There is an urgent need for standardization of STs, training of qualified personnel, suitable equipment, and certification. These are essential conditions for a reliable diagnosis of $C F$, especially with the increasing demand due to NBS nationwide, and for the assessment of a possible clinical benefit with the use of CFTR modulator drugs.

\section{ACKNOWLEDGEMENTS}

Cystic Fibrosis Collaborative Study Group: Francisco Ubaldo Vieira Junior, Margarida Duarte Amaral, Neiva Damaceno, Joaquim Carlos Rodrigues, Giesela Fleischer Ferrari, Vera Lucia Sdepanian, João Batista Salomão Junior, Sônia Mayumi Chiba, Sônia Letícia Silva Lorena, and Maria Inêz Machado Fernandes.

\section{REFERENCES}

1. Levy $H$, Farrell PM. New challenges in the diagnosis and management of cystic fibrosis. J Pediatr. 2015;166(6):1337-41. https://doi.org/10.1016/j.jpeds.2015.03.042

2. Cystic Fibrosis Data Network [homepage on the Internet]. Belconnen, Australia: Geoff Sims Consulting Pty Ltd.; c2013 [cited 2016 Feb 2]. Cystic fibrosis data. Available: http://www.cysticfibrosisdata.org/ Home.htm

3. Raskin S, Pereira-Ferrari L, Reis FC, Abreu F, Marostica P, Rozov T, et al. Incidence of cystic fibrosis in five different states of Brazil as determined by screening of p.F508del, mutation at the CFTR gene in newborns and patients. J Cyst Fibros. 2008;7(1):15-22. https://doi. org/10.1016/j.jcf.2007.03.006

4. Camargos P, Gomes DL, Alvim CG, Gomes FS, Cajazeiro JM. From lip to lab: salty tasting skin is the main clue that raises clinical suspicion of cystic fibrosis in young infants. Acta Paediatr. 2015;104(5):e210-5. https://doi.org/10.1111/apa.12958

5. Dijk FN, Fitzgerald DA. The impact of newborn screening and earlier intervention on the clinical course of cystic fibrosis. Paediatr Respir Rev. 2012;13(4):220-5. https://doi.org/10.1016/j.prrv.2012.05.003

6. Vernooij-van Langen AM, Gerzon FL, Loeber JG, Dompeling E, Dankert-Roelse JE. Differences in clinical condition and genotype at time of diagnosis of cystic fibrosis by newborn screening or by symptoms. Mol Genet Metab. 2014;113(1-2):100-4. https://doi. org/10.1016/j.ymgme.2014.07.012

7. van der Ploeg CP, van den Akker-van Marle ME, Vernooij-van Langen AM, Elvers LH, Gille JJ, Verkerk PH, et al. Cost-effectiveness of newborn screening for cystic fibrosis determined with real-life data. J Cyst Fibros. 2015;14(2):194-202. https://doi.org/10.1016/ . jcf.2014.08.007

8. Smyth AR, Bell SC, Bojcin S, Bryon M, Duff A, Flume P, et al European Cystic Fibrosis Society Standards of Care: Best Practice guidelines. J Cyst Fibros. 2014;13 Suppl 1:S23-42. https://doi. org/10.1016/j.jcf.2014.03.010

9. Gibson LE, Cooke RE. A test for concentration of electrolytes in sweat in cystic fibrosis of the pancreas utilizing pilocarpine by iontophoresis. Pediatrics. 1959;23(3):545-9.

10. Collie JT, Massie RJ, Jones OA, LeGrys VA, Greaves RF. Sixty-five years since the New York heat wave: advances in sweat testing for cystic fibrosis. Pediatr Pulmonol. 2014;49(2):106-17. https://doi. org/10.1002/ppul.22945

11. Cystic Fibrosis Foundation [homepage on the Internet]. Bethesda: the Foundation; [cited 2016 Feb 2]. Available: https://www.cff.org/

12. Cirilli N, Padoan R, Raia V; ICFS Sweat Test Working Group. Audit of sweat testing: a first report from Italian Cystic Fibrosis Centres. J Cyst Fibros. 2008;7(5):415-22. https://doi.org/10.1016/j.jcf.2008.03.005

13. LeGrys VA, Yankaskas JR, Quittell LM, Marshall BC, Mogayzel PJ $\mathrm{Jr}$; Cystic Fibrosis Foundation. Diagnostic sweat testing: the Cystic Fibrosis Foundation guidelines. J Pediatr. 2007;151(1):85-9. https:// doi.org/10.1016/j.jpeds.2007.03.002

14. Farrell PM, Rosenstein BJ, White TB, Accurso FJ, Castellan C, Cutting GR, et al. Guidelines for diagnosis of cystic fibrosis in newborns through older adults: Cystic Fibrosis Foundation consensus report. J Pediatr. 2008;153(2):S4-S14. https://doi org/10.1016/j.jpeds.2008.05.005

15. Castellani C, Southern KW, Brownlee K, Dankert Roelse J, Duff A Farrell $\mathrm{M}$, et al. European best practice guidelines for cystic fibrosis neonatal screening. J Cyst Fibros. 2009;8(3):153-73 https://doi org/10.1016/j.jcf.2009.01.004

16. Lezana JL, Vargas $\mathrm{MH}$, Karam-Bechara J, Aldana RS, Furuya ME. Sweat conductivity and chloride titration for cystic fibrosis diagnosis in 3834 subjects. J Cyst Fibros. 2003;2(1):1-7. https://doi. org/10.1016/S1569-1993(02)00146-7

17. US National Committee for Clinical Laboratory Standards. Sweat testing: sample collection and quantitative analysis; approved guideline. 2nd ed. Waynes (PA): US National Committee for Clinica Laboratory Standards; 2000 Jun. Document No: C34-A2.

18. US National Committee for Clinical Laboratory Standards. Sweat testing: sample collection and quantitative analysis; approved guideline. 3rd ed. Waynes (PA): US National Committee for Clinical Laboratory Standards; 2009 Dec. Document No: C34-A3.

19. LeGrys VA. Sweat analysis proficiency testing for cystic fibrosis Pediatr Pulmonol. 2000;30(6):476-80. https://doi.org/10.1002/10990496(200012)30:6<476::AID-PPUL7>3.0.CO:2-0

20. LeGrys VA. Assessment of sweat-testing practices for the diagnosis of cystic fibrosis. Arch Pathol Lab Med. 2001;125(11):1420-4.

21. Baumer $\mathrm{JH}$. Evidence based guidelines for the performance of the sweat test for the investigation of cystic fibrosis in the UK. Arch Dis Child. 2003;88(12):1126-7. https://doi.org/10.1136/adc.88.12.1126

22. Ramsey BW, Davies J, McElvaney NG, Tullis E, Bell SC, Dřevínek $P$, et al. A CFTR potentiator in patients with cystic fibrosis and the G551D mutation. N Engl J Med. 2011;365(18):1663-72. https://doi. org/10.1056/NEJMoa1105185

23. Wainwright CE, Elborn JS, Ramsey BW, Marigowda G, Huang $X$ Cipolli M, et al. Lumacaftor-Ivacaftor in Patients with Cystic Fibrosis Homozygous for Phe508del CFTR. N Engl J Med. 2015;373(3):22031. https://doi.org/10.1056/NEJMoa1409547

24. Quinton P, Molyneux L, Ip W, Dupuis A, Avolio J, Tullis E, et al. $\beta$-adrenergic sweat secretion as a diagnostic test for cystic fibrosis. Am J Respir Crit Care Med. 2012;186(8):732-9. https://doi. org/10.1164/rccm.201205-09220C

25. Gonska T, Ip W, Turner D, Han WS, Rose J, Durie P, et al. Sweat gland bioelectrics differ in cystic fibrosis: a new concept for potentia diagnosis and assessment of CFTR function in cystic fibrosis. Thorax 2009;64(11):932-8. https://doi.org/10.1136/thx.2009.115295

26. Sousa, M, Servidoni MF, Vinagre A, Ramalho AS, Bonadia LC, Felício $\mathrm{V}$, et al. Measurements of CFTR-mediated $\mathrm{Cl}$ - secretion in human rectal biopsies constitute a robust biomarker for Cystic Fibrosis diagnosis and prognosis. PLoS One. 2012;7(10):e47708. https://doi. org/10.1371/journal.pone.0047708

27. Gonçalves AC, Marson FA, Mendonça RM, Ribeiro JD, Ribeiro $A F$, Paschoal IA, et al. Saliva as a potential tool for cystic fibrosis diagnosis. Diagn Pathol. 2013;8:46. https://doi.org/10.1186/17461596-8-46

28. Ng RT, Marson FA, Ribeiro JD, Ribeiro AF, Bertuzzo CS, Ribeiro MA et al. Nasal potential difference in cystic fibrosis considering severe CFTR mutations. Dis Markers. 2015;2015:306825

29. Instituto Brasileiro de Geografia e Estatística [homepage on the Internet]. São Paulo: IBGE; c2016 [cited 2016 Feb 2]. Estados@-São Paulo: Botucatu. [about 3 screens]. Available from: http://www.ibge. gov.br/estadosat/perfil.php?sigla=sp

30. Kirk JM. Inconsistencies in sweat testing in UK laboratories. Arch Dis Child. 2000;82(5):425-7. https://doi.org/10.1136/adc.82.5.425

31. Mackay R, George P, Kirk J. Sweat testing for cystic fibrosis: A review of New Zealand laboratories. J Paediatr Child Health. 2006;42(4):160 4. https://doi.org/10.1111/j.1440-1754.2006.00822.x

32. Marson FA, Hortencio TD, Aguiar KC, Ribeiro JD; CYFIUC Group. Demographic, clinical, and laboratory parameters of cystic fibrosis during the last two decades: a comparative analysis. BMC Pulm Med. 2015;15:3. https://doi.org/10.1186/1471-2466-15-3 